\title{
Bronchodilator reversibility in patients with COPD revisited: short-term reproducibility
}

\author{
This article was published in the following Dove Press journal: \\ International Journal of COPD \\ 29 August 2016 \\ Number of times this article has been viewed
}

\author{
Steven Pascoe \\ Wei $\mathrm{Wu}^{2}$ \\ Chang-Qing Zhu ${ }^{3}$ \\ Dave Singh ${ }^{4}$ \\ 'GSK, Respiratory Medicines \\ Development Center, ${ }^{2}$ PAREXEL \\ International, Research Triangle Park, \\ NC, USA; ${ }^{3}$ GSK, Clinical Statistics \\ (Respiratory), Middlesex, UK; \\ ${ }^{4}$ Medicines Evaluation Unit, University \\ Hospital of South Manchester NHS \\ Foundation Trust, University of \\ Manchester, Manchester, UK
}

\begin{abstract}
Categorization of patients with COPD as reversible or nonreversible to a bronchodilator may change over time. This post hoc analysis aimed to determine if an individual's reversibility, when treated as a continuous variable, could predict his/her future response to two short-acting bronchodilators: albuterol and ipratropium. The analysis was completed using data from a 4-week, randomized, open-label, two-period crossover study (NCT01691482; GSK study DB2114956). Patients received albuterol (doses: UK $=4 \times 100 \mu \mathrm{g} / \mathrm{puff} ; \mathrm{US}=4 \times 90 \mu \mathrm{g} / \mathrm{puff}$ ) followed 1 hour later by ipratropium $(4 \times 20 \mu \mathrm{g} /$ puff) or vice versa during treatment Period 1 . The order of treatments was reversed during Period 2. Predefined efficacy end points included pre- and post-bronchodilator forced expiratory volume in 1 second. The correlation coefficient between bronchodilator response on Days 1 and 10 was investigated, as well as the correlation between treatment response on Day 1 and the mean treatment response on Days 5-10, for each individual patient. Bronchodilator response to albuterol on Day 1 was strongly correlated with that on Day $10(r=0.64 ; \mathrm{n}=53)$. The correlation coefficient of bronchodilator treatment response on Day 1 and Days 5-10 was $0.78(P<0.001 ; \mathrm{n}=53)$ and $0.76(P<0.001 ; \mathrm{n}=54)$ for albuterol and ipratropium, respectively. A single measurement of the initial bronchodilator response to albuterol or ipratropium was, therefore, highly correlated with the subsequent mean bronchodilator response over 5-10 days, demonstrating its potential usefulness for future treatment decisions.
\end{abstract}

Keywords: bronchodilator responsiveness, $\mathrm{FEV}_{1}$, correlation, short-acting bronchodilators, spirometry

\section{Introduction}

COPD is characterized by persistent airflow limitation. ${ }^{1,2}$ Inhaled $\beta_{2}$-agonists and antimuscarinics have become central to the management of patients with COPD, as they improve lung function. ${ }^{2}$ Improvements in exercise tolerance and quality of life, and reductions in COPD symptoms including exacerbations have also been demonstrated with these treatments. ${ }^{2}$ Long-acting bronchodilators are used as regular maintenance therapies in patients with moderate-to-severe COPD, while short-acting bronchodilators are generally used as required to provide symptomatic relief. ${ }^{2}$

Despite little evidence to suggest a bimodal distribution of bronchodilator response with two distinct groups of responders and nonresponders, ${ }^{3,4}$ the paradigm of the reversible and nonreversible COPD phenotype has been widely applied to classify patients in clinical trials. ${ }^{5-8}$ However, bronchodilator responsiveness may be considered a continuous variable, ${ }^{9}$ with the effect of bronchodilators on lung function varying substantially between patients. ${ }^{2,10}$ The $200 \mathrm{~mL}$ cut-off point used to establish reversibility ${ }^{6}$ is close to the mean forced expiratory volume in 1 second $\left(\mathrm{FEV}_{1}\right)$ response of patients with $\mathrm{COPD}$ to albuterol (eg, Buhl et al reported mean $\mathrm{FEV}_{1}$ values of $164-177 \mathrm{~mL}$ in a population
Correspondence: Steven Pascoe GSK, Respiratory Medicines Development Center, 5 Moore Drive, Research Triangle Park, NC 27709-3398, USA

Tel + I 9194918859

Email steven.j.pascoe@gsk.com 
of 5,162 patients $^{11}$ ), and therefore, the categorization of a patient as reversible or not reversible may not be consistent over time. ${ }^{9,12}$ Based on these findings, Calverley et al recommended that the dichotomized outcome of classifying patients as reversible or not reversible should be abandoned. ${ }^{9}$

As a result of the issues surrounding bronchodilator responsiveness, the relationship between baseline reversibility and clinical outcomes or diagnoses has been questioned. 3,6,12 For example, in an analysis of the Understanding Potential Long-term Improvements in Function with Tiotropium (UPLIFT) study, the authors concluded that baseline bronchodilator responsiveness to ipratropium and albuterol, when assessed using three distinct categories, was not predictive of clinically important outcomes with tiotropium. ${ }^{6}$ In another study, when lack of reversibility to bronchodilators was used as a diagnostic marker for COPD, there was an underdiagnosis of COPD. ${ }^{3}$ It is now accepted that bronchodilator reversibility should not be included in diagnostic criteria for COPD. ${ }^{2}$ However, bronchodilator reversibility is still measured in many research studies and clinical trials to characterize patients, and is used routinely in clinical practice as the post-bronchodilator $\mathrm{FEV}_{1}$ is used for diagnosis of COPD. ${ }^{3,6-8,13}$

We recently reported that the free combination of the short-acting bronchodilators albuterol (a $\beta_{2}$-agonist) and ipratropium (a muscarinic antagonist) led to lower day-today variability in $\mathrm{FEV}_{1}$ compared with either monotherapy. ${ }^{14}$ Here, we report a novel post hoc analysis of data from this clinical study, investigating the reproducibility of treatment response to a short-acting bronchodilator by considering reversibility as a continuous variable, rather than "reversible" or "nonreversible".

\section{Methods}

\section{Study design}

This was a post hoc analysis of a 4-week, randomized, openlabel, two-period crossover study performed at two study centers specializing in spirometry (one in the UK, one in the US), between July 2012 and February 2013 (NCT01691482; GSK study number DB2114956). ${ }^{14}$ Patients were $\geq 40$ years of age, were current or former smokers with a smoking history of $\geq 10$ pack-years, had a previous physician diagnosis of COPD,${ }^{1}$ had a post-albuterol $\mathrm{FEV}_{1} /$ forced vital capacity ratio $<0.70$, and a post-albuterol $\mathrm{FEV}_{1}$ of $\geq 30 \%$ and $\leq 70 \%$ of predicted normal. Concomitant use of inhaled corticosteroids at a stable dose was permitted. Patients with a current diagnosis of asthma or any clinical significant uncontrolled disease were excluded. ${ }^{14}$

Patients were randomized 1:1 to receive albuterol (GlaxoSmithKline, Middlesex, UK) via metered dose inhaler (doses:
$\mathrm{UK}=4 \times 100 \mu \mathrm{g} /$ puff; US $=4 \times 90 \mu \mathrm{g} /$ puff), followed by ipratropium 1 hour later $(4 \times 20 \mu \mathrm{g} / \mathrm{puff}$; Boehringer Ingelheim, Ingelheim, Germany) or vice versa, during treatment Period 1 (10-14 days). The order of treatments was then reversed during treatment Period 2. Placebo was administered on Day 4 in both study periods. There was no washout stage between Periods 1 and 2. ${ }^{14}$ At each visit (except for Day 4 of each study period [Visits 5 and 15]), pre-dose spirometry was performed, followed by the administration of either albuterol or ipratropium. Spirometry was repeated 1 hour after administration (Figure S1). On Day 4 of each study period, spirometry readings were taken at approximately the same times (ie, at 0 and 1 hour). At each study visit, patients were asked to refrain from smoking for 1 hour prior to the first pulmonary function test and throughout the study visit, until after the last spirometry test had been performed. ${ }^{14}$ The analyses detailed in this study were completed for both albuterol and ipratropium. The study protocol and any amendments were reviewed and approved by a national, regional, or investigational center ethics committee or institutional review board (Manchester Evaluation Unit, Manchester, UK: D2012-2166-E02-UK; Chesapeake institutional review board, SC, USA: PRO0007141). Written informed consent was obtained from each patient prior to initiation of any study procedures.

\section{Outcomes and assessments}

Full details on outcomes and assessments for the DB2114956 study have been previously published. ${ }^{14}$ The post hoc analyses presented in this study focused on the bronchodilator treatment response in terms of $\mathrm{FEV}_{1}$, defined as the change in $\mathrm{FEV}_{1}$ at 1 hour (post-dose) from 0 hour (pre-dose) on each day. Initial exploratory post hoc analyses examined the correlation coefficient of $\mathrm{FEV}_{1}$ response between Day 1 and Day 10. The mean within-patient difference in $\mathrm{FEV}_{1}$ response (including the proportion of patients exhibiting differences of $<100, \geq 100$ to $<150, \geq 150$ to $<200$, and $\geq 200 \mathrm{~mL}$ ) between these days was also calculated. The correlation coefficient of bronchodilator treatment response on Day 1 and the mean treatment response on Days 5-10, for each individual patient, were also investigated. Additional post hoc analyses included the following: 1) the correlation coefficient of the mean treatment response for Days 1-2 and Days 1-3 with the mean response during Days 5-10, for each individual patient; and 2) the stability of each individual patient's status as reversible or nonreversible on Day 1 compared with Day 10. Reversibility was defined as an increase in $\mathrm{FEV}_{1}$ of $\geq 12 \%$ and $\geq 200 \mathrm{~mL}$ following administration of albuterol or ipratropium. 


\section{Statistical analyses}

Time-dependent bronchodilator responses to albuterol or ipratropium were assessed by correlation coefficient analyses. The pairwise linear correlation coefficients of $\mathrm{FEV}_{1}$ at pre-dose (0 hour) and 1 hour post-dose were computed by treatment and by day to assess the individual effect of albuterol or ipratropium over time. These post hoc analyses did not take study period into consideration.

The overall analysis population was defined as all patients who were randomized and completed pre- and post-bronchodilator assessments for at least 17 visits, with no more than 3 consecutive missing days. All programming was performed using SAS version 9 (SAS Institute Inc., Cary, NC, USA) and S-Plus version 7. (TIBCO Software Inc, CA, USA).

\section{Results}

Overall, 70 patients were screened, 56 were randomized to treatment and received at least one dose of bronchodilator in the treatment period (intent-to-treat population), and 53 patients completed the study. One patient in the intent-to-treat population was excluded from the efficacy population due to missing study visits for more than 3 consecutive days; therefore, data from 55 patients were analyzed. Baseline characteristics of the patients have been previously published. ${ }^{14}$ Briefly, patients had a mean age of 60.3 years (standard deviation [SD]: 7.42 years) and a mean predicted $\mathrm{FEV}_{1}$ post-albuterol at screening of $51.33 \%$ (SD: 9.87\%). The mean $\mathrm{FEV}_{1}$ reversibility at the screening visit was $193 \mathrm{~mL}$ (SD: $188 \mathrm{~mL}$ ), and the mean percentage reversibility was $19.54 \%$ (SD: $17.39 \%$ ). Twenty-six (46\%) patients were considered reversible (defined as an increase in $\mathrm{FEV}_{1}$ of $\geq 12 \%$ and $\geq 200 \mathrm{~mL}$ following administration of albuterol) at screening, and 30 (54\%) were nonreversible.

The correlation coefficient of individual bronchodilator treatment response (change in $\mathrm{FEV}_{1}$ from 0 to 1 hour postdose) to albuterol on Day 1 with that on Day 10 was 0.64 (Figure 1). The mean response to albuterol was $261 \mathrm{~mL}$ on

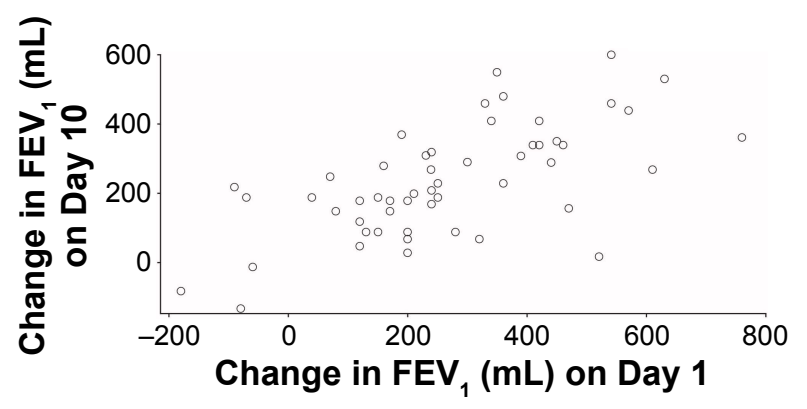

Figure I Response to albuterol on Day I compared with Day 10. Abbreviation: $\mathrm{FEV}_{1}$, forced expiratory volume in I second.
Table I Mean changes and mean difference between absolute change in $\mathrm{FEV}_{\text {, }}$ on Day I and Day 10

\begin{tabular}{|c|c|c|}
\hline & Day I & Day 10 \\
\hline Albuterol, $\mathrm{n}$ & 55 & 53 \\
\hline Mean $(\mathrm{n})$ change in $\mathrm{FEV},(\mathrm{SD})(\mathrm{mL})$ & 261 (199) & $237(158)$ \\
\hline $\begin{array}{l}\text { Mean }(\mathrm{n}) \text { difference between Day I } \\
\text { and Day } 10(\mathrm{SD})(\mathrm{mL})^{*}\end{array}$ & & $47(I I 2)$ \\
\hline Ipratropium, n & 55 & 54 \\
\hline Mean $(\mathrm{n})$ change in FEV $(\mathrm{SD})(\mathrm{mL})$ & $253(180)$ & $24 I(163)$ \\
\hline $\begin{array}{l}\text { Mean }(n) \text { difference between Day I } \\
\text { and Day } 10(S D)(m L) *\end{array}$ & & $27(170)$ \\
\hline
\end{tabular}

Note: *The mean difference was calculated using the number of patients with data available on Day 10.

Abbreviations: $\mathrm{FEV}_{1}$, forced expiratory volume in I second; SD, standard deviation.

Day 1 and $237 \mathrm{~mL}$ on Day 10, with a mean within-patient difference (Day 1 vs Day 10) of $47 \mathrm{~mL}$ (Table 1). The mean response to ipratropium was $253 \mathrm{~mL}$ on Day 1 and $241 \mathrm{~mL}$ on Day 10, with a mean within-patient difference (Day 1 vs Day 10) of $27 \mathrm{~mL}$ (Table 1). There was wide variability in the mean $\mathrm{FEV}_{1}$ responses to both treatments, as demonstrated by the associated SD values (Table 1). Out of 53 patients who received albuterol on Day 1 and Day 10, 31 (58\%) had a response to albuterol on Day 10 that was $<100 \mathrm{~mL}$ different to their response on Day 1; a similar proportion of patients $(\mathrm{n}=28 ; 52 \%)$ met this criterion for ipratropium at Day 10 (Table 2).

The correlation coefficient of bronchodilator treatment response on Day 1 and the mean of Days 5-10 was $0.78(P<0.001)$ and $0.76(P<0.001)$ for albuterol and ipratropium, respectively. The correlation coefficient of bronchodilator treatment response over the means of Days $1-2(0.85$ and 0.81 for albuterol and ipratropium, respectively) and Days 1-3 (0.88 and 0.84) with the means of Days 5-10 increased (compared with Day 1 and Days 5-10) for both bronchodilators.

At Day 10, 42 out of 53 (79\%) patients receiving albuterol had not changed their reversibility status (defined as an increase in $\mathrm{FEV}_{1}$ of $\geq 12 \%$ and $\geq 200 \mathrm{~mL}$ following administration of albuterol or ipratropium) from Day 1 (reversible

Table 2 Difference in FEV, response to albuterol and ipratropium between Day I and Day I0, stratified by specific thresholds

\begin{tabular}{lll}
\hline $\begin{array}{l}\text { Difference between Day I } \\
\text { and Day } \mathbf{~} \mathbf{0}(\mathbf{m L})\end{array}$ & $\begin{array}{l}\text { Albuterol, } \\
\mathbf{n}=\mathbf{5 3}\end{array}$ & $\begin{array}{l}\text { Ipratropium, } \\
\mathbf{n}=\mathbf{5 4}\end{array}$ \\
\hline$<100$ & 31 & 28 \\
$\geq 100$ to $<150$ & 12 & 8 \\
$\geq 150$ to $<200$ & 4 & 9 \\
$\geq 200$ & 6 & 9 \\
\hline
\end{tabular}

Notes: *One patient completed the ipratropium study period but not the albuterol study period; therefore, $\mathrm{n}=53$ for albuterol and $\mathrm{n}=54$ for ipratropium.

Abbreviation: $\mathrm{FEV}_{1}$, forced expiratory volume in I second. 


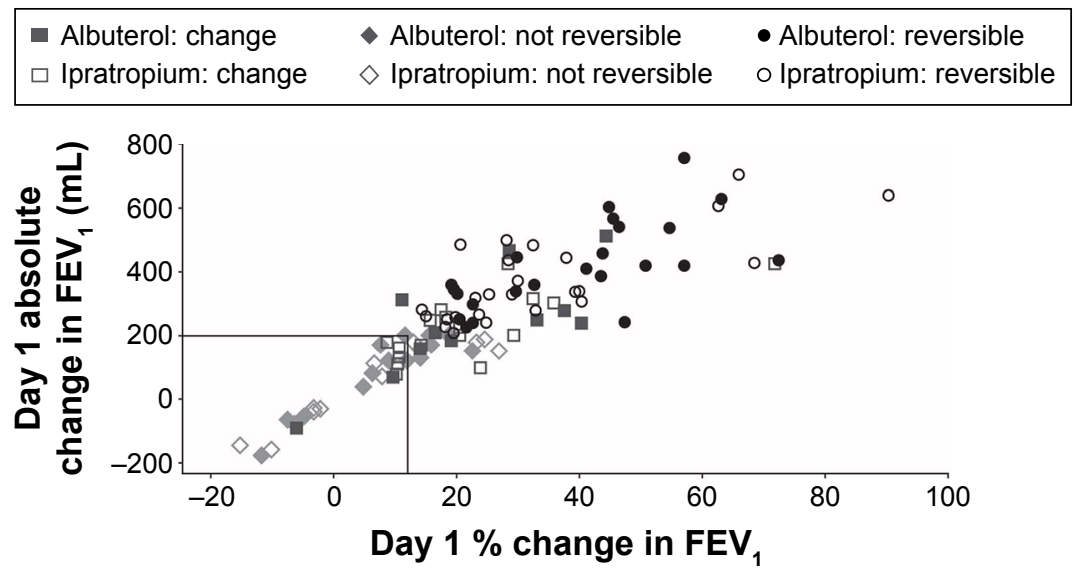

Figure 2 Change in FEV, on Day I for albuterol and ipratropium.

Notes: Symbols demonstrate "reversibility" status on Day 10. Reversibility was defined as an increase in FEV of $\geq 12 \%$ and $\geq 200 \mathrm{~mL}$ following administration of albuterol or ipratropium. The square symbols represent patients whose reversibility status changed between Day I and Day 10.

Abbreviation: $\mathrm{FEV}_{1}$, forced expiratory volume in I second.

at both days: $n=24$ [45\%]; nonreversible at both days: $n=18$ [34\%]; Figure 2). For ipratropium, at Day 10, 37 out of $54(69 \%)$ patients had not changed their status from Day 1 (reversible at both days: $\mathrm{n}=25$ [46\%]; nonreversible at both days: $n=12$ [22\%]). Patients who had a change in reversibility status tended to have $\mathrm{FEV}_{1}$ values clustered around the cut-off point used to define reversibility in this study (Figure 2).

\section{Discussion}

There was substantial variability of the $\mathrm{FEV}_{1}$ response to albuterol and ipratropium between patients. However, the mean within-patient difference in response to albuterol or ipratropium between Days 1 and 10 was relatively small: $47 \mathrm{~mL}$ and $27 \mathrm{~mL}$, respectively. The bronchodilator response on Day 1 showed a good correlation with the response on Day $10(r=0.64)$ which improved when the average response on subsequent occasions (Days 5-10) was used. Overall, these results suggest that the short-term repeatability of bronchodilator reversibility tests is generally good with stable responses being observed for most measurements. This was supported by the observation that the majority of patients did not change reversibility status between Day 1 and Day 10 .

As might be expected, those patients who changed reversibility status in this study had values clustered around the binary cut-off point for reversibility. Previous studies have reported varying proportions of patients changing reversibility status, dependent on the criteria employed: $75 \%-79 \%$ by Hanania et al, ${ }^{6} 38 \%$ and $52 \%$ by Calverley et al, ${ }^{9}$ and $11 \%$ and $18 \%$ by Albert et al. ${ }^{12}$ The different proportions reported across these studies could be due to a variety of factors, including the exclusion of patients with a higher magnitude of response, ${ }^{9}$ the use of different cut-off points, ${ }^{6,9}$ the use of long-acting bronchodilators within the trials, and potential variability due to spirometric procedures between centers. In order to limit any spirometric measurement variations, this study was conducted in two centers specializing in spirometric measurements.

The issues with selecting a cut-off point can be illustrated with the data from a large study. ${ }^{11}$ In this study, the mean response in $\mathrm{FEV}_{1}$ to albuterol was $164-177 \mathrm{~mL}$ but with SD values of $138-150 \mathrm{~mL}$. This implied that $68 \%$ of patients (the percent of patients in any normal population who are within one SD of the mean ${ }^{15}$ ) were $<138-150 \mathrm{~mL}$ from the mean response. ${ }^{11}$ It should therefore be no surprise that a large number of patients when retested would cross any arbitrary boundary (eg, $200 \mathrm{~mL}$ ) near the mean value of this distribution due solely to the error inherent in the measurement of $\mathrm{FEV}_{1}$. Three previous studies that tested different cut-off points for bronchodilator response found that all criteria produced inconsistent results. ${ }^{6,9,12}$ Consequently, the Global initiative of chronic Obstructive Lung Disease guidelines no longer recommend the use of reversibility for diagnosis of COPD or for prediction of future clinical outcomes. ${ }^{2}$ As our study results support the findings of Calverley et al, ${ }^{9}$ we suggest that future studies investigating the association of bronchodilator response with clinical outcomes should include bronchodilator response as a continuous, not dichotomized, variable.

This study had limitations. It was a post hoc analysis of data from an exploratory study, and as such should be treated with a degree of caution, but given that the correlations seen were statistically significant to a very high degree and other components of the analysis were purely descriptive, the findings warrant consideration and further investigation. A drawback of the study was its short duration. Long-term 
studies are required to determine if these findings are transferable over longer time frames.

Overall, we believe our study shows that bronchodilator responsiveness is a consistent variable within an individual patient over the short term, but highly variable between patients. With the measurement error inherent in spirometry in routine clinical practice, or even across multiple centers in large studies, we are cautious of suggesting that measuring a spirometric response may predict an individual's likelihood of achieving sustained benefit from bronchodilators. However, the results presented in this study do suggest that accurate measures of bronchodilation may be able to predict future response at the individual level over the short term.

\section{Disclosure}

This study was funded by GSK (DB2114956). Editorial support in the form of developing the first draft based on author input, referencing, editing, and incorporation of author comments was provided by Gillian Groeger, $\mathrm{PhD}$, and Natasha Thomas, PhD, Fishawack Indicia Ltd, UK, and funded by GSK. S Pascoe and C-Q Zhu are employees of GSK and own GSK stock. W Wu was an employee of GSK at the time this study was completed but is currently employed by PAREXEL International. D Singh declares he has received sponsorship to attend international meetings, honoraria for lecturing or attending advisory boards, and research grants from various pharmaceutical companies including Almirall, AstraZeneca, Boehringer Ingelheim, Chiesi, Genentech, Glenmark, GSK, Johnson and Johnson, Merck, NAPP, Novartis, Pfizer, Skypharma, Takeda, Teva, Theravance, and Verona. The authors report no other conflicts of interest in this work.

\section{References}

1. Celli BR, MacNee W; ATS/ERS Task Force. Standards for the diagnosis and treatment of patients with COPD: a summary of the ATS/ERS position paper. Eur Respir J. 2004;23(6):932-946.
2. Global Initiative for Chronic Obstructive Lung Disease. Global strategy for the diagnosis, management and prevention of Chronic Obstructive Pulmonary Disease. 2016. Available from: http://www.goldcopd.org/. Accessed March 18, 2016.

3. Kjeldgaard P, Dahl R, Lokke A, Ulrik CS. Detection of COPD in a high-risk population: should the diagnostic work-up include bronchodilator reversibility testing? Int J Chron Obstruct Pulmon Dis. 2015;10: $407-414$.

4. Tashkin D, Kesten S. Long-term treatment benefits with tiotropium in COPD patients with and without short-term bronchodilator responses. Chest. 2003;123(5):1441-1449.

5. Celli BR, Tashkin DP, Rennard SI, McElhattan J, Martin UJ. Bronchodilator responsiveness and onset of effect with budesonide/formoterol pMDI in COPD. Respir Med. 2011;105(8):1176-1188.

6. Hanania NA, Sharafkhaneh A, Celli B, et al. Acute bronchodilator responsiveness and health outcomes in COPD patients in the UPLIFT trial. Respir Res. 2011;12(1):6.

7. Singh D, Pujol H, Ribera A, et al. A dose-ranging study of the bronchodilator effects of abediterol (LAS100977), a long-acting beta2-adrenergic agonist, in asthma; a Phase II, randomized study. BMC Pulm Med. 2014; $14: 176$.

8. Tashkin DP, Celli B, Decramer M, et al. Bronchodilator responsiveness in patients with COPD. Eur Respir J. 2008;31(4):742-750.

9. Calverley PM, Burge PS, Spencer S, Anderson JA, Jones PW. Bronchodilator reversibility testing in chronic obstructive pulmonary disease. Thorax. 2003;58(8):659-664.

10. Anthonisen NR, Lindgren PG, Tashkin DP, Kanner RE, Scanlon PD, Connett JE. Bronchodilator response in the lung health study over 11 yrs. Eur Respir J. 2005;26(1):45-51.

11. Buhl R, Maltais F, Abrahams R, et al. Tiotropium and olodaterol fixeddose combination versus mono-components in COPD (GOLD 2-4). Eur Respir J. 2015;45(4):969-979.

12. Albert P, Agusti A, Edwards L, Tal-Singer R, Yates J, Bakke P, et al. Bronchodilator responsiveness as a phenotypic characteristic of established chronic obstructive pulmonary disease. Thorax. 2012;67(8): 701-708.

13. Montes de Oca M, Perez-Padilla R, Talamo C, et al. Acute bronchodilator responsiveness in subjects with and without airflow obstruction in five Latin American cities: the PLATINO study. Pulm Pharmacol Ther. 2010;23(1):29-35.

14. Singh D, Zhu CQ, Sharma S, Church A, Kalberg CJ. Daily variation in lung function in COPD patients with combined albuterol and ipratropium: results from a 4-week, randomized, crossover study. Pulm Pharmacol Ther. 2014;31:85-91.

15. StatSoft Inc. Electronic Statistics Textbook. Tulsa, OK: StatSoft; 2013. Available from: http://www.statsoft.com/textbook/. Accessed March 18, 2016. 


\section{Supplementary material}

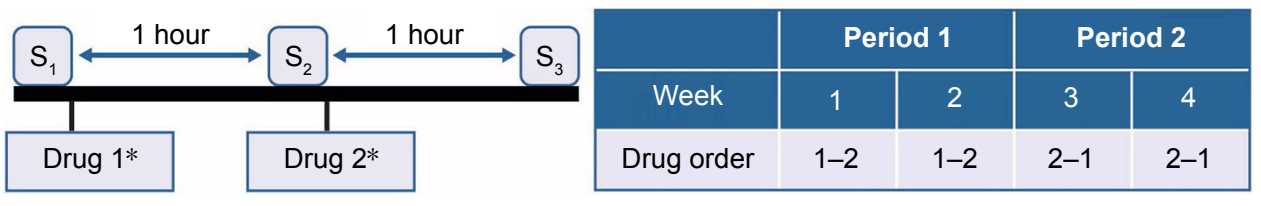

Figure SI Schematic diagram of the study design.

Notes: *Drugs administered immediately after spirometry. $\mathrm{S}_{1}$ : pre-dose spirometry; $\mathrm{S}_{2}$ : spirometry I hour after drug I; $\mathrm{S}_{3}$ : spirometry I hour after drug 2.

\section{Publish your work in this journal}

The International Journal of COPD is an international, peer-reviewed journal of therapeutics and pharmacology focusing on concise rapid reporting of clinical studies and reviews in COPD. Special focus is given to the pathophysiological processes underlying the disease, intervention programs, patient focused education, and self management protocols.
This journal is indexed on PubMed Central, MedLine and CAS. The manuscript management system is completely online and includes a very quick and fair peer-review system, which is all easy to use. Visit http://www.dovepress.com/testimonials.php to read real quotes from published authors. 